\title{
Hot Corrosion and Degradation in Complex Atmospheres
}

\author{
Michel Vilasi • Bruce Pint • Daniel Monceau
}

Published online: 1 March 2013

(C) Springer Science+Business Media New York 2013

Presented in this focus issue of Oxidation of Metals are key papers that deal with hot corrosion and degradation in complex atmospheres. This specific topic is commonly addressed because numerous industrial applications face several imposed constraints such as reduction of $\mathrm{CO}_{2}$ emissions or limitation in fossil fuel reserves. Specific industrial examples are power generation and urban waste incineration.

The atmospheres encountered in many advanced industrial processes are very rarely single oxidant, as illustrated by most of combustion gases which invariably contain carbonaceous species, water vapour, and quite commonly sulfur species derived from the impurities present in most fossil fuels. In addition, liquid phases are likely to be formed and deposited on the surface of components as a result of interactions between the combustion gases and the inorganic compounds present in the atmosphere such as halide, sulfate, carbonate or aluminosilicate salts. In such cases, aggravated degradation of materials is expected due to the superpositioning of chemical-degradation processes e.g., oxidation and oxide dissolution by acidic or basic fluxing.

The following key papers stem from presentations that were given at the 8th international conference on High Temperature Corrosion and Protection of Materials (HTCPM2012), which was held at Les Embiez Island, France, on the 20-25th of May 2012.

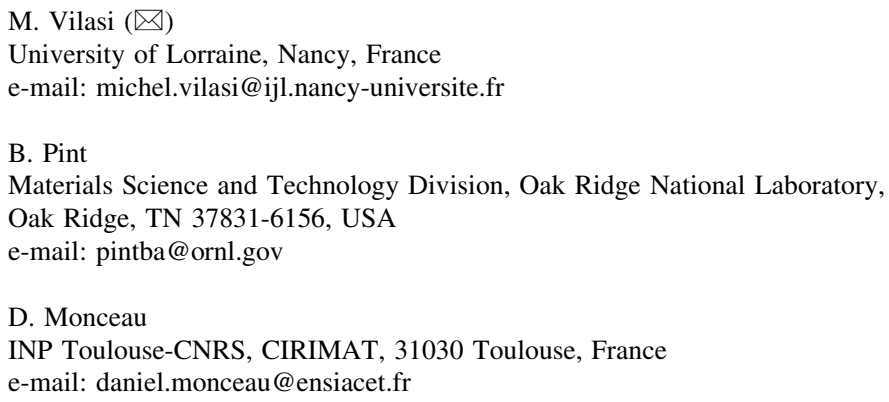


The papers presented in this topical issue cover a large number of corrosive environments, particularly sulfidizing-carburizing-oxidizing mixed gas, deposit of fluxing liquids like sulfates and chlorides, and commercial and model alloys e.g., carbon, ferritic, austenitic and martensitic steels, nickel-based superalloys. The industrial applications are mainly relevant to energy production e.g., nuclear and conventional fossil power plants, biomass gasification, urban waste incineration, gas turbine, and exhaust systems. Within this extended and complex framework of corrosive environments, experimental results are discussed and interpreted on the basis of established thermodynamic data which are activities of metals, partial pressure-fugacity of gases, composition and temperature of eutectics, scaling of corrosion products. Moreover, key parameters for advancing fundamental understanding of sulphate-deposit-induced hot corrosion are highlighted. This understanding requires a detailed understanding of: $i$. phase equilibria and eutectic composition in multicomponent systems versus temperature, ii. molten salt chemistry, iii. oxide protectiveness versus stability in molten salts and alloy composition. 